INVESTIGACIONES

\title{
HACIA UNA RECUPERACION DE LA SUBJETIVIDAD EN EL PROCESO DE CONOCER EN EL CONTEXTO ESCOLAR: LA PREGUNTA POR EL SABER EN NIÑOS Y NINTAS DE EDUCACION BASICA CHILENA
}

\author{
TOWARDS A RECOVERY OF SUBJECTIVITY IN THE PROCESS OF LEARNING IN THE SCHOOL \\ CONTEXT: THE QUESTION OF THE CHILDREN KNOWLEDGE IN THE \\ CHILEAN PRIMARY SCHOOL
}
Recuperando a subjetividade no processo do conhecer dentro do contexto escolar: a pergunta pelo saber das crianças que cursam o ensino básico chileno

\author{
Mónica Peña Ochoa* \\ Facultad de Psicología, Universidad Diego Portales \\ monica.pena@udp.cl
}

\section{RESUMEN}

Este artículo se basa en una investigación que busca recuperar las voces de niños y niñas en el proceso de conocer dentro de la escuela, considerando que la niñez se desarrolla a partir de contextos socioculturales determinados. Por otro lado, el conocimiento para la educación equivaldría a la adquisición de la razón y la verdad, atentando contra los estilos de conocimiento infantil. El modelo metodológico es cualitativo con uso de técnicas visuales, donde el investigador deja el protagonismo adultocéntrico y se lo cede a los entrevistados de entre 10 y 11 años de escuelas privadas y municipalizadas chilenas. Los resultados indican que el aprendizaje es entendido por los sujetos entrevistados como una forma de control social, la experiencia infantil tiene un lugar relevante como forma de relación con el mundo y su lugar en la sociedad y la cultura es más bien pobre y limitado.

Palabras clave: niñez, escuela, educación, conocimiento.

\begin{abstract}
This article is based on a research that seeks to recover the children voices in the learning process within the school, considering childhood as a socio-cultural group. On the other hand, knowledge for the education amount to the acquisition of reason and truth, attacking styles of children's knowledge. The methodological model is qualitative through the use of visual techniques, where the researcher assigns enormous importance to the respondents, aged between 10 and 11 years of private schools and publics schools in Chile. The results indicate that the subjects interviewed understood learning as a social control way, the childhood experience has an important place in their relationship with the world and their place in society and culture is rather poor and limited.
\end{abstract}

Key words: childhood, school, education, knowledge.

\section{RESUMO}

Este artículo se basea em una pesquisa que busca recuperar as vozes das crianças no processo do conhecer dentro da escola, considerando que a infancia se desenvolve a partir de contextos socio-culturais determinados. Por outro lado, o conhecimento para a educação equivaleria à aquisição da razão e da verdade, atentando contra os estilos de conhecimento infantil. O modelo metodológico é qualitativo com o uso de técnicas visuais, nas quais o pesquisador deixa o seu protagonismo adultocêntrico e o cede aos entrevistados, crianças que têm entre 10 e 11 anos e que frequentam escolas privadas e municipalizadas chilenas. Os resultados indicam que a aprendizagem é entendida pelos sujeitos entevistados como uma forma de controle social, que a experiência infantil tem um lugar relevante como uma forma de relação com o mundo, e que o seu lugar na sociedade e na cultura é pobre e limitado.

Palavras-chave: infancia, escola, educação, conhecimento.

\footnotetext{
* Investigación financiada por CONICYT.
} 


\section{INTRODUCCION}

La siguiente investigación surge de algunos supuestos problemáticos que parecen no tener urgencia en el modelo educativo actual, pero sin duda son parte importante de la arquitectura educacional, aquella que parece estar en una constante crisis. Esos supuestos son los siguientes:

- Los alumnos, en particular aquellos que se encuentran en la etapa de niñez, han sido concebidos como figuras unidimensionales por parte del mundo adulto. Por ejemplo, la psicología del niño o del desarrollo es una de las disciplinas que se han hecho cargo de este problema desde una perspectiva por lo general maniquea. Las teorías del aprendizaje tradicionales, por su parte, se caracterizan por dibujar a un niño neutro, análogo a un recipiente que simplemente recibe el saber del otro. El cambio hacia modelos constructivistas, por tanto, debe pasar necesariamente por la reflexión acerca de la subjetividad de aquellos que se involucran en el aprendizaje.

- Dentro del sistema educacional chileno no se ha analizado el lugar del saber y del conocimiento como hecho subjetivo, es decir, el conocimiento como constituido en el sujeto y relacionado con el otro, contextualizado a una realidad particular. Las pocas reflexiones que se han desarrollado en el área del saber y el conocimiento se dirigen a la técnica, en algunos pocos casos a la epistemología, pero sistemáticamente se ha ignorado el protagonismo de los alumnos como "sujetos de saber", sujetos que a la vez son parte de una institución muy particular: la escuela. Asimismo, cualquier conocimiento construido por los sujetos infantiles tiende a ser negado o, al menos, ignorado.

En un mundo donde el conocimiento aún se debate en un modelo racional y unidireccional, es posible preguntarse ¿cuál es el estatus del saber y el conocimiento en los niños y niñas chilenas? Y principalmente ¿cuál es la perspectiva de los propios niños en tanto sujetos de sus propios procesos de aprendizaje? ¿Cómo es la relación que ellos tienen con el saber dentro de una institución normativa como la escuela?

\section{ANTECEDENTES TEORICOS}

\section{A) MODERNIDAD, INFANCIA E INSTITUCION EDUCATIVA}

Tradicionalmente, la tendencia ha sido considerar a la infancia o niñez como un estado natural y universal, que se caracteriza por ser inestable y transitorio en tanto es un proceso de desarrollo, tensionado siempre a la adultez. Sin embargo, es posible enfrentar de manera crítica estos supuestos que transforman a los niños y niñas en objetos que crecen pasivamente, que correlacionan el desarrollo psicológico y social con el desarrollo físico (Burman, 1994).

La infancia es un grupo sociohistóricamente constituido, que se conforma en principio como consecuencia de las organizaciones familiares que varían según la evolución del aparato productivo (Ariés, 1973). Es un error pensar que la infancia comparte las mismas 
características en independencia del lugar geográfico, social o histórico en que se sitúe, y también es equivocado pensar que es posible estudiar a la infancia con independencia de factores como género, clase social y etnicidad (James, 1997). Es necesario entonces tomar en cuenta que para la investigación cualitativa en el área de infancia (así también en el tema de la adolescencia y juventud) es fundamental explicitar las condiciones sociales, históricas y económicas del grupo social estudiado.

La modernidad parece ser el espacio en que se desarrolla la infancia como la entendemos actualmente, gracias a la reorganización de las estructuras familiares a partir de los cambios en el aparato productivo, y debido también al rol activo del Estado, con la institución escolar (Ariés, 1973; Donzelot, 1990; Shorter, 1975; Salazar, 1990, 2003). La llegada de la modernidad supone una nueva organización social donde la educación tiene un rol preponderante en la consolidación de un nuevo hombre que es parte ahora de un cuerpo social (lo que Rousseau llamó "El contrato social"). Es por eso que la escuela es fundamentalmente un espacio normativo, uniformador, centrado en la preparación del individuo para la convivencia y para el trabajo, cada vez más especializado en el mundo contemporáneo.

El caso chileno no dista de lo descrito, a pesar de que hay importantes distinciones necesarias de llevar a cabo. Una forma de entender el proceso de la familia chilena y las identidades de infancia es el concepto del huacho que se encuentra en la relación simbiótica de madre e hijo, con ausencia no sólo del padre, sino de una imagen masculina asociada. La palabra Huacho proviene del quechua Huachuy: cometer adulterio. Designa tanto al hijo ilegítimo como al huérfano. Además, se utiliza para denominar al animal que se ha separado de su rebaño (Montecinos, 1991). El varón ausente, el lacho, deja en manos del niño la búsqueda de la adultez en el macho, mientras que la niña sólo logra configurar su rol de género en la maternidad, identificada a su madre sola. El hombre chileno, el "peón", trabajaba a ración y sin salario, por lo que muchos se iniciaban en el vagabundaje en busca de trabajos esporádicos o de la delincuencia. Los procesos económicos son fundamentales: las crisis económicas provocaban la salida del padre del grupo familiar y la creencia de que los hijos eran un lastre. La infancia en Chile aparece sellada por su precocidad en tanto su destino quedaba marcado tempranamente: el huacho se vuelve pelusa y el pelusa bandido (Salazar, 1990, pp. 55-72).

Cifras de mediados del siglo XX demuestran que la mitad de los niños chilenos son nacidos fuera del matrimonio (Illanes, 1991), lo que cooperaría con una economía familiar de sustento, para el surgimiento de una problemática social contra la cual la naciente institucionalidad debía luchar. El niño entonces es un sujeto que debe ser integrado a las aulas "ganándoselo" a la calle o a la caridad de la élite conservadora, que construiría su propia red de ayuda a niños, niñas y madres principalmente.

El huacho pasa a ser parte del mito colectivo del Chile bastardo, mestizo, de la vergüenza (Montecino, 1991). La palabra Huacho era un insulto, ya que ponía en evidencia la falta de padre y más claramente la falta del nombre de éste, es decir, la falta de origen y lugar en la sociedad (Milanich, 2001).

El fenómeno de la bastardía tendría relación con tres fenómenos nacionales presentes desde los inicios de la República: El primero y más obvio, las grandes crisis económicas que asolaron al país durante el siglo XX, principalmente las de los años 30, 53 y 83, que obligarían a reconfigurar el panorama doméstico de las familias chilenas, con un gran impulso a la emigración desde el campo a la ciudad con la consabida pobreza de 
los cordones urbanos. Así los niños saldrían a trabajar a la calle ${ }^{1}$ para sustentarse a ellos y al resto de la familia.

El segundo fenómeno es el de un matriarcado débil apoyado por una aristocracia conservadora. El hombre que ha tenido que salir de la familia al mundo del trabajo asalariado se vuelve un ser peligroso: el alcoholismo se transformará en el fantasma que se lleva a los varones de la casa, dejando a la mujer y a los niños solos (Salazar, 2003).

El tercer fenómeno es la vagancia infantil (Ibíd.) como principal consecuencia, que incluye las problemáticas de la prostitución y la delincuencia. En Chile entonces queda establecido: el niño no es necesariamente parte de la familia, en muchos casos carece de ella siendo su espacio la calle, como parte del paisaje urbano.

Los niños trabajadores, vagos y desnutridos que consigna la historia chilena en la primera mitad del siglo XX se estrellan contra una escuela que podía tener los brazos abiertos para recibirlos ${ }^{2}$, pero que no estaba hecha para contener a tal población. Así, pasaron años antes de que la escuela y los grupos sociales de la época se adaptaran a los cambios de la educación masiva que el frágil Estado chileno proponía.

Existió una dura competencia entre la calle y la escuela: mientras la calle ofrecía el alimento diario, la escuela no, siendo más bien un gasto sin retornos evidentes para las familias. El niño en Chile, lejos de la visión romántica del triunfo de la civilización sobre la barbarie, es alejado de la calle en gran parte gracias a la continua integración de la alimentación escolar al aula, acción privada y estatal que se llevó a cabo durante gran parte del siglo XX (Illanes, 1991).

La tesis de una escuela de encierro a la vez que benefactora amplía el prisma político con que ha sido analizada la educación en Chile. Este origen y rol fundamental de los establecimientos escolares, por sobre el tema de la enseñanza, el aprendizaje o el saber genera una tensión clara a partir de la necesidad de construir una nación desde la ayuda social, donde la escuela tendría un rol cardinal en lo asistencial, con una tradición pedagógica fundada en el encierro de los niños y jóvenes que pululaban por las calles, a la manera de una guardería. La ilusión de una escuela que nace a partir de los deseos de prosperidad hacia los más desamparados, o como motor principal del desarrollo, no tolera más análisis que el histórico: nuestra escuela obligatoria se genera a partir de la consideración del niño como un peligro para la sociedad.

\section{B) EL SABER, LA VERDAD Y LA INSTITUCION ESCOLAR}

Esta realidad no es contradictoria con el rol pedagógico tradicional de la escuela, ya que la educación formal se desarrolla bajo la idea de fomentar los procesos de la razón por sobre la sinrazón: la verdad por sobre la falsedad. La tradición cartesiana confía en que hay un método racional de acceso a la verdad, método que la infancia no tiene (Foucault, 1973). Es por ello que los modelos relativos a la experiencia en primera persona, donde el constructivismo toma un lugar trascendental, y el modelo de aprendizaje de la

\footnotetext{
1 De acuerdo a la encuesta de hogares CASEN en Chile, en 1990 cerca del 7\% de los niños entre 12 y 17 años participaba de la fuerza de trabajo, para el 2000 ese porcentaje bajó a un 4\%, lo que significa un total de 64.954 niños a nivel nacional (Solari, 2002).

2 La Ley de Instrucción Primaria Obligatoria se promulgó en 1920, no obstante la escolaridad primaria completa se alcanzó en los años 60 .
} 
escuela moderna no tienen porqué ser coherentes. Responden a tradiciones diferentes y sus énfasis son otros. No obstante, ha existido un esfuerzo por tratar de hacer conexiones entre ambas perspectivas, llevando los nuevos modelos de conocimiento a la institución educativa, con distintos resultados.

Un Yo sustancia, espacio limitado y cognoscible debe construirse en la razón. Por eso es posible decir desde esta perspectiva que ni el niño ni el loco poseen razón, y que por lo tanto su Yo es incompleto, está cercenado. El Yo, esa ilusión, en forma dictatorial se ha tomado a los sujetos, rige desde la ética del deber ser en tanto es posible alinear este Yo a un discurso de lo prudente, de lo propio, de lo nuestro, es decir, de la norma social. Es lo otro que queda excluido, en palabras de Foucault, es por eso que hay peligro en que la gente hable y que sus discursos proliferen indefinidamente (Ibíd.).

El sujeto del paradigma racional tradicional ha quedado instalado en el lugar del Yo ontológico, pura sustancia que se relaciona con el mundo -externo e independiente- gracias a la razón. Este Yo está moldeado por la razón obtenida de la conciencia de ignorancia, a través de la actitud de reducción cartesiana, e instalado en la búsqueda de la verdad o en la "voluntad de verdad" de Foucault (Ibíd.), verdad que está puesta en lo dicho por el discurso. De estas ideas se desprende que también la exclusión opera sobre el discurso del niño: El niño no es racional, por ende sus proposiciones no pueden calificarse de verdaderas, asumiendo que al estar en la ignorancia se encuentra automáticamente en la falsedad. El niño estaría puesto del lado de la obediencia y el acatamiento de las proposiciones verdaderas, que siempre están fuera de él, transformando la entrega del conocimientos en un dispositivo de control, así como la ignorancia es -a la vez- un dispositivo de exclusión.

El niño como sujeto en el proceso de conocimiento queda atrapado dentro de dos puntos trascendentales: el niño como sujeto racional y el niño como sujeto dominado. Ambos puntos son dos caras de la misma moneda: aquella que dice relación con una falta respecto de lo adulto, una falta que resta al niño como sujeto frente a nuestras construcciones culturales.

¿Hay relación entre la noción de subjetividad y el conocimiento? Es posible concebir que existe un sujeto que se configura en la relación con el mundo, y este sujeto es, desde la perspectiva racional, la de un Yo cartesiano que actúa desde la razón excluyendo la experiencia. Es posible partir de esta idea en el rescate de la subjetividad del niño en la escuela, a pesar de que no es sencillo configurar una teoría epistemológica desde la educación, ya que el tema de la educación no es el conocimiento. El conocimiento en la educación suele encontrarse en la base de ciertas miradas pero no configura el ethos ni la finalidad de la educación.

Cuando enfrentamos el conocimiento desde la Educación, éste queda generalmente opacado por los conceptos de contenido y aprendizaje. El término conocimiento es entendido en forma transversal como contenido, es decir, como material constituido para el aprendizaje. Por su parte, el conocimiento como acción, es decir, el concepto "conocer" es usado en forma muy limitada, utilizándose en cambio como verbo el concepto aprendizaje o el binomio enseñanza-aprendizaje. El concepto aprendizaje se centra en el concepto de tomar algo de fuera para incorporarlo (aprehender), por lo que se sitúa dentro de un modelo representacionista de la realidad.

Sin embargo, el panorama es alentador a pesar de la insistencia en leer desde la perspectiva racionalista tradicional el problema de la experiencia infantil. La lectura de 
Piaget presenta este problema interpretativo (Varela, 2000). Es posible hablar del conocimiento integrado a la teoría cognitiva de mediados del siglo $\mathrm{XX}$, como un concepto dinámico que, fundamentado en la obra de Piaget (1959, 1967, 1975), da cuenta de un proceso experiencial por parte de un sujeto sin hacer referencia a los objetos externos que deberían adquirirse o asimilarse. Piaget logra demostrar que los niños son capaces de tener sus propias hipótesis mediante la asimilación en sus estructuras del mundo exterior, así como les es posible la acomodación en la realidad de sus hipótesis. Piaget sostiene que los niños no se transforman naturalmente en adultos (y de hecho es un error poner madurez cognitiva y adultez como sinónimos) y que la formación de la psique no es una continuación progresiva y acumulativa de representaciones del mundo exterior, sino que el conocimiento se construye en estadios identificables cualitativamente, tiene una psicogénesis y no se origina en tábulas rasas. Desde esta perspectiva, las modalidades de enseñanza actuales son advertidas como modelos dirigidos a generar conocimiento que quedan pequeños y deben reformularse.

\section{METODOLOGIA}

Esta investigación de carácter cualitativo usa las técnicas visuales para la recogida de datos (Harper, 2002; Hazel, 1995; Banks, 1995). Estas técnicas se vienen usando con fuerza los últimos años especialmente en el campo de la infancia, ya que permiten subsanar un problema que la investigación tradicional trae aparejada con la figura del investigador/sabio, que a través de sus preguntas va dirigiendo la respuesta en los sujetos investigados, principalmente cuando estos son niños y pueden identificar fácilmente al entrevistador adulto con una figura de autoridad.

Por otra parte, el uso de la imagen es útil para trabajar con discursos infantiles, los que desde una perspectiva racional -como se vio- con facilidad son tildados al menos de "precarios". Lo imaginario - desde una perspectiva racionalista- queda puesto en los bordes de una mente que debería estar concentrada en realidades y no en simples imágenes. No obstante, traer a colación lo imaginario ha sido la consecuencia de una tradición semántica contemporánea que valora el signo como símbolo y como concepto. Lo imaginario como lo contrario de lo racional, la imagen como la superficie de la palabra, la imaginación como un ejercicio fútil que se relaciona con la ausencia de verdad en tanto no es real. La imaginación como sinónimo de creatividad para unos pocos. Imagen como sinónimo de ilusión.

Sin embargo, la imagen no es pura superficie, sino que por el contrario, está cargada de significaciones. Retomando la técnica del dibujo, es a través de la imagen que muchos niños logran comunicarse, pero no por la imposibilidad discursiva propiamente tal sino por la estructuración psíquica que se va dando a través, básicamente, de la imagen del cuerpo: "En los niños y en los psicóticos que no pueden hablar directamente de sus sueños y fantasías como lo hacen los adultos con la asociación libre, la imagen del cuerpo es para el sujeto la mediación para hacerlo, y para el analista el medio para conocerlo" (Dolto, 1984: 67). La autora aclara respecto a la literalidad de la interpretación de la imagen: "La imagen del cuerpo no es la imagen dibujada o representada en el modelado; ha de ser revelada en el diálogo analítico con el niño" (Ibíd.). Precisa que es a través de la escucha de los acontecimientos de la historia personal del niño que éste, mediante su 
palabra, va desanudando el conflicto libidinal que siempre es del orden de lo simbólico, es decir, siempre tiene un significado posible de asir e interpretar.

Para este trabajo se constituyó un denominado "Dispositivo de escucha", que consiste en la organización de un espacio con características particulares que pretende generar condiciones generales para el despliegue discursivo del sujeto entrevistado. El concepto de dispositivo es un concepto amplio, usado por Foucault (1980) para referirse a las relaciones de poder, pero que ha ido desarrollándose hasta llegar a conformar la explicación de una modalidad de relación subjetiva amplia que se basa en las relaciones entre individuos, desde la experiencia propia. Foucault describiría un conjunto heterogéneo que incluye discursos, instituciones, instalaciones arquitectónicas, decisiones reglamentarias, leyes, medidas administrativas, enunciados científicos, proposiciones filosóficas, morales, filantrópicas, lo dicho y también lo no-dicho, éstos son los elementos del dispositivo. Para el autor, el dispositivo mismo es la red que se establece entre estos elementos (Ibíd.). Deleuze aclara: "Las dos primeras dimensiones de un dispositivo, o las que Foucault distingue en primer término, son curvas de visibilidad y curvas de enunciación. Los dispositivos... son máquinas para hacer ver y para hacer hablar... Cada dispositivo tiene su régimen de luz, la manera en que ésta cae se esfuma, se difunde, al distribuir lo visible y lo invisible, al hacer nacer o desaparecer el objeto que no existe sin ella" (Deleuze, 1987: 108).

El proceso de una entrevista donde se usa la imagen fotografiada de los sujetos es en sí entonces un proceso de subjetivación, que trae a lo real -a través de una escenificación-, las relaciones del sujeto consigo mismo, con el otro y con el medio que lo sustenta: su propia imagen bordada en el lenguaje. La fotografía no es una imagen superficial, no obstante es simplemente una demostración más de cómo la identidad de los sujetos se construye de forma frágil, imaginaria y temporal, lejos de los esencialismos rígidos que impiden la evolución y la tolerancia de las distintas identidades.

La entrevista propuesta debe cumplir entonces con las siguientes condiciones:

a) Estructurarse en torno al sujeto que habla y no al entrevistador. Es básicamente guiada por la imagen del propio hablante y su realidad como estímulo significativo y es dirigida por el entrevistado. Las técnicas de elicitación se caracterizan, en parte, por "un diálogo que se basa más en la autoridad del entrevistado que la del investigador". (Harper, 2002: 15).

b) Permitir la diversidad discursiva. Esto implica que la entrevista no se define ni como estructurada ni como semiestructurada, ya que no hay temáticas más que las que surgen de la imagen fotográfica, que se constituye como fenómeno emergente en el momento de la entrevista. Se considera que la imagen en sí tiene una cualidad polisémica (Deleuze, 1985), ya que el entrevistado no responde a un estímulo único o a una pregunta que pueda ser contestada desde la expectativa socialmente correcta. En otras palabras, parece dirigirse más a los imaginarios que a las representaciones.

Las imágenes tampoco sustentan su valor en la descripción. Aunque algunos niños partían por describir lo que estaba plasmado -enumeración por lo demás familiar, organizada, casi aburrida- tenían como único mandato hablar de lo que primero se les ocurriera. Es ahí cuando muchos de ellos hacen la pausa y reconocen lo observado más allá de las 
figuras sino que a partir de los significados propios que han construido en la experiencia, ya a estas alturas ( $5^{\circ}$ y $6^{\circ}$ año de educación básica), vasta y profunda.

Se entrevistaron 22, la mitad varones y mujeres de un colegio particular pagado de la Región Metropolitana, y la otra mitad varones y mujeres de una escuela municipalizada de la V Región. Las fotos se sacaron durante octubre y noviembre del año 2005, en horario de clases, mientras se hacían clases regulares, con la presencia de al menos un profesor. Se sacaba un set de fotos de más o menos 20 imágenes y, durante la misma semana que fueron sacadas, fueron llevadas a cabo las entrevistas en dependencias de los establecimientos educacionales.

\section{RESULTADOS Y DISCUSION}

El material que se generó a través de la entrevista visual se organizó fundamentalmente alrededor de las concepciones de aprendizaje, apareciendo como temas idiográficos las concepciones de éxito y fracaso escolar, rol de los docentes, rol de la familia, convivencia escolar, entre otros. Es posible organizar estos resultados como sigue:

Los niños de ambos tipos de escuelas atribuyen su éxito escolar a la influencia familiar, así como sus fracasos son atribuidos a la escuela o a la incapacidad individual: en ningún caso el aprendizaje lo atribuyen a la labor del profesor. Los niños de escuela privada suelen además culpar del fracaso escolar específicamente a los profesores, quienes serían como empleados que brindan un servicio, el de "enseñar". Algunos niños especifican que sus habilidades son heredadas de sus padres, o que se deben a sus clases particulares o a que provienen de un colegio con mejor formación que el actual.

Los niños de escuela privada construyen expectativas acerca de sus oportunidades a futuro, las que están ligadas a su proceso de escolarización. Niños y niñas de 10 y 11 años tienen conciencia de que el éxito escolar es una parte importante de su desarrollo posterior. Por su parte, los niños de la escuela municipalizada aspiran a un cambio radical en sus vidas (un viaje, un cambio de escuela, un cambio de barrio) para optar a mejores oportunidades, viendo de manera negativa su lugar de origen. Son los niños de proveniencia municipalizada quienes más se refirieron a su barrio y a sus hogares, generalmente en términos negativos, ya que la principal aspiración es salir de ahí. Sin embargo, la educación no es vista como la forma más obvia de progreso social, a menos que sea una educación para el trabajo.

Otro punto fundamental es el orden en el aula: la organización del espacio gobernado por el docente, donde los cuerpos tienen un lugar fundamental en la consecución del aprendizaje a través de la atención que es entendida como la mirada hacia el profesor, hacia el pizarrón. Quien no se somete a este orden es considerado negativamente por el resto.

\section{A) EL APRENDIZAJE COMO CONTROL}

Es posible decir a partir de los resultados que el proceso de enseñanza es entendido como una forma de control, por ende, el aprendizaje se transforma en una forma de obediencia. No obstante, este discurso no está dirigido desde la queja, sino que es aceptado por los entrevistados como el fin y el fondo de la educación escolar. Sin duda, para los 
entrevistados la educación se asemeja a un proceso de control que es dirigido por el profesor-adulto, donde el aprendizaje pasa a ser uno de los dispositivos disciplinarios por excelencia de la institución, la regla del juego básica.

Ahora bien, la niñez ha sido parte de esta idea del aprendizaje control que se desprende de la mirada racionalista dirigida a los resultados observables. El sistema de aprendizaje medido (llevado a cabo a través de objetivos evaluables que determinan si hubo aprendizaje) parece ser entendido como un proceso de acopio realizado a través de dos herramientas: la atención y la concentración.

La atención es la consecuencia esperada de una posición deliberada del cuerpo en el espacio, donde la cabeza enfrenta el material con el que se aprende, ya sea el profesor, el pizarrón o cualquier elemento, incluyendo aquellas llamadas "las nuevas tecnologías" de tipo electrónico. La cabeza, para el niño que aprende, se transforma en el instrumento primordial: por ahí se ve y se escucha. Que los niños estén mirando para otro lado o que hablen mientras el profesor habla, genera desorden dentro de un orden bien configurado: mirar al frente y escuchar una sola voz, la del profesor. Este orden garantizaría el aprendizaje, como la entrada de los contenidos disciplinares que a su vez han sido ya ordenados por el docente.

El orden del cuerpo se organiza en torno a la posición de la cabeza. Más allá de que el profesor se encuentre al frente, es el docente quien dictamina hacia dónde se mira. Para aprender hay que mirar y escuchar lo ordenado por el profesor y ese orden es una línea unidireccional. Si el profesor deja las palabras a los alumnos nadie hace nada, es decir, cuando la soberanía del cuerpo queda en manos de cada individuo no hay aprendizaje, sólo desorden. Las clases de corte participativo, como por ejemplo, los consejos de curso, parecen ser espacios anárquicos, aun cuando el profesor diga "esta clase la hacen ustedes". Algunos alumnos rechazan tajantemente este tipo de prácticas en el aula: la labor del profesor debe ser guiar la clase para que haya real aprendizaje, y uno de sus deberes incluye ordenar los cuerpos. En el caso de quien decida no alinearse al orden de los cuerpos, no sólo es castigado por salirse de la norma o de los actos de aula esperados, sino que se espera que ese sujeto en cuestión fracase, ya que no está en la línea de montaje del aprendizaje.

El concepto de orden no es una simple visión estática de los cuerpos sino que es de una maquinaria precisa en constante movimiento, donde el que no cumple con el rigor industrializado es penado, no sólo por el profesor sino por los propios alumnos, todos pendientes de que la máquina funcione. El que se sale de la cadena queda afuera, y no sólo fracasa él, sino que hace tambalear toda la línea de producción. De ahí que los niños entre ellos se transformen en constantes vigías del comportamiento ajeno y que, en definitiva, sean comunes dentro del aula las conductas ofensivas e incluso discriminatorias hacia aquellos que con sus conductas disruptivas tambalean la línea productiva.

La concepción de este aprendizaje fijado en la línea predeterminada de montaje, inmovilizado a la vez que móvil, hace patente la idea tradicional de que la no acción (orientada al aprendizaje) equivale a no aprendizaje. Las clases que no responden a la línea son poco toleradas por los propios estudiantes. Los profesores que permiten desórdenes son malos profesores, pero aquel que los controla es justificado, ya sea porque los niños y niñas deben ser enderezados por su "natural" tendencia al desorden o porque no cumplen el rol de ser la autoridad de la sala correspondiente a la imagen del adulto. 
La relevancia que tiene la atención para los niños es central, ya que existe la creencia de que el aprendizaje se instala en sus cabezas siempre y cuando el canal no se rompa, y ese canal pasa por dirigir todo esfuerzo a la persona del profesor. La distracción es evitada, negada o atacada en tanto se asume que quienes se someten a ella "no están pensando". El viejo problema de la inutilidad de la inacción, que pocos autores han abordado: es fácil olvidar que hasta la conducta más simple está llena de sentido, que el reposo no es un espacio vacío (Merleau-Ponty, 1953).

Asimismo, en este ambiente donde el aprendizaje es una finalidad individual, existe un fuerte sentido de competencia, constituyéndose estilos de convivencia caracterizados por el mal clima afectivo entre los alumnos. Es fácil ver cómo se clasifican entre los más y los menos capacitados para el logro del aprendizaje, cómo aquellos que se destacan positiva o negativamente son rechazados y anulados por el resto de los compañeros de clases.

\section{B) EL LUGAR DE LA EXPERIENCIA}

Si la relación con el aprendizaje es a través del control, la relación con el saber de los niños y niñas se configura a través del gusto. Si bien ya no es el gusto evidenciado en la oralidad, es el gusto por las cosas lo que conforma y organiza su realidad. "Me gusta" o "no me gusta" es una frase propia de la infancia, poco permitida en la adultez, justamente por ser el reflejo más fiel de la temida subjetividad. El gusto como tal, heredero de aquellas experiencias directas con la realidad, a través del tacto, del sabor, del aroma, aún surge con fuerza en los escolares. Les gusta o no un profesor, un compañero, un ramo o asignatura, como les gusta también un color, un sabor, un olor. El mundo aún es un espacio a degustar para poder incorporar, para hacer propio y constituirlo como realidad. El estadio sensorio-motriz propuesto por Piaget, aquella primera etapa que consiste en sentir el mundo para conocerlo, deja resabios en los sujetos, se mantiene como forma de conocer el mundo y, tal como lo plantea Piaget (1967, 1975), no como un estadio temporal cerrado sino como una modalidad de conocimiento originaria y siempre presente en los modelos de conocer que se adquieren con posterioridad.

Espontáneamente en el discurso infantil, la temática del gusto es iterativa. Sus preferencias suelen ser muy personales y cambiantes. Les puede gustar la profesora cuando enseña pero no cuando impone reglas. No está la obligación de la "consecuencia", no hay un ordenamiento racional para estos gustos. Sin embargo, es interesante rescatar uno de los elementos más llamativos en el discurso infantil de estos más de 20 niños: la poca atracción que genera entre los niños las matemáticas y el idioma inglés.

Si bien la preferencia en sus gustos varía, por ejemplo, a algunos les gusta lenguaje, a otros "comprensión del medio", a otros la educación física y a otros arte; tanto matemáticas como inglés son las asignaturas que obtienen las menores expresiones de agrado y más expresiones de molestia y desagrado.

Sólo dos de los entrevistados manifestaron su gusto por las matemáticas: una niña que las prefiere porque "son prácticas", porque no tiene que leer, sólo practicar, y un niño que dice que le gustan porque le sale fácil, ya que heredó la habilidad de su madre contadora. Los que no las aprecian dicen que es porque son fomes ${ }^{3 *}$ o porque no las entienden. Frente a algo que no entiendo, dejo de poner atención activa, me hago consciente

3 Aburridas. 
del minuto, por lo tanto me aburro. Esta sensación en algunos niños es angustiosa, les genera un intenso temor, no sólo a la asignatura sino a todos los actos de aula asociados: salir a la pizarra, contestar, preguntar, ser evaluados. Los profesores son identificados a esta sensación negativa, tornándose en personas non-gratas.

El profesor toma el lugar negativo: "Me cae mal", "es pesada", "es enojona", "tiene mal humor". El lugar del docente queda demarcado como la bandera del desagrado. Si la profesora es pesada, es más difícil subirse al carro del aprendizaje, porque la necesito a ella para que me guíe y esa guía tiene que ser confortable. Tal como se mencionó, pocos casos caracterizaron al profesor como un buen enseñante ${ }^{4}$, mientras que la mayoría prefirió definir al profesorado en tanto sus características de amabilidad y simpatía.

Es posible observar que ambas asignaturas tienen algo en común: son dos lenguas distintas a las maternas, son dos formas de insertarse a nuevas realidades, otras formas de conectarse con el mundo. Sin embargo, no es posible que asocien estas lenguas con sus usos en otras realidades. La desconexión es enorme entre el aprendizaje de inglés en el aula y el deseo de viajar a otros países por ejemplo, como si lo que se aprende en el aula no sirviera para la vida, queja antigua que se refleja en el abismo entre el currículo y la vida, que los niños remarcan con sus expectativas, las que no parecen ir de la mano con las experiencias obtenidas en el aula.

En matemáticas, su simbología es compleja, su alfabeto desconocido, sus sonidos desesperanzadores: "son puro número" dice un niño, cansado de no entender, a pesar de que explica con detalles que antes se sacaba un 6 y ahora un 2. Es decir, vive en un mundo de números pero no es posible para él entrar a esta realidad, que siempre parece una realidad otra. ¿Es la realidad que representa consecuencia de un poder al que no se puede acceder? Las matemáticas vividas como "el" saber, como el reflejo de la verdadera inteligencia, se tornan en un muro alto y difícil de sortear. Las consecuencias de mantenerse detrás de este muro serán más crueles según pase el tiempo y las necesidades de los niños aumenten y las exigencias se tornen peores. Quedarse fuera de este mundo tendrá un precio bastante caro, en tanto las disciplinas que mandan en el mundo actual se escriben desde el lenguaje matemático.

Los docentes de las asignaturas poco apreciadas heredan la falta de aprecio. Se personifica en ellos el desprecio por estas lenguas ignotas, se les ve como lejanos a las necesidades de los alumnos. Son ellos quienes en definitiva desplazan a una realidad abstracta el mundo matemático, el mundo de la lengua, a través de las necesidades de la institución: avanzar, cumplir objetivos, obtener resultados. Por otro lado, los niños, en su rol de alumnos, compartimentan sus habilidades en falsos grupos de disciplinas. Si las matemáticas no son su fuerte, lo serán las letras, el ser "humanista", como una salida por descarte del mundo de los números es una salida común. Esta especialización temprana podría tener importantes consecuencias en los logros de los alumnos en tanto aún es posible mejorar las capacidades operatorias y postoperatorias de estos niños de 10 y 11 años. Estas capacidades aún pueden desarrollarse desde una perspectiva más bien experiencial, donde ellos puedan interesarse en el mundo de los elementos formales y no en la pizarra que estampa en forma estática un número. Desde otro punto de vista, la especialización es una forma de prejuicio, de cierre perceptivo hacia nuevas realidades donde simplemente ya no se hace el esfuerzo por conocer.

4 Uno de los niños entrevistados dijo que le gustaba la profesora porque era "enseñativa". 
Actualmente, los modelos didácticos de las matemáticas se debaten desde una matemática platónica, donde la labor del aprendiz es descubrir el mundo matemático, a modelos más experienciales como el piagetano. Para Piaget, el número es una noción que se aprende después de haber pasado por la etapa sensorio-motriz, aproximadamente a los 5 años de edad. Consecutivamente se obtendrán nuevas habilidades, de lo más concreto a lo más abstracto, para el aprendizaje matemático, las nociones de permanencia y conservación de longitud, masa y volumen, que facilitarán los procesos de reversibilidad, necesarios para las operaciones lógico-matemáticas abstractas. No obstante, estos modelos constructivistas clásicos se encuentran con variaciones más contemporáneas como aquellas propias del constructivismo social, que consideran que las matemáticas se adquieren en los procesos cotidianos, mientras que es posible que cognitivamente hayan estructuras muy básicas que permitan su aprendizaje. La noción de cantidad, por ejemplo, ha sido descubierta en animales y niños muy pequeños. Estas nuevas miradas confluyen en un aprendizaje matemático que da lugar, por ejemplo, a las intuiciones numéricas antes que a los conceptos abstractos, a los procesos semiempíricos antes que a los ejercicios formales (Font, 2003).

\section{C) REPENSANDO LA RELACION NIÑEZ-INSTITUCION}

Finalmente, es importante repensar el lugar de niños y niñas: ¿Es suficiente pensar la infancia como un grupo que se mueve entre la escuela y la familia? El niño -cuando mira hacia fuera de la escuela- ve a la familia. La familia como red de apoyo, donde escasamente el mundo público se hace un espacio: Es la familia el lugar de la oportunidad a través del tío, la abuela o el hermano que va a tender una mano para ayudar al niño en su desarrollo. Como el presente parece estar condicionado por el pasado genealógico, para los niños de los ambos grupos, el futuro se observa a través de las redes familiares en la obligación del parentesco.

La familia podría ser entendida también como reflejo del hilo privatizador que ha cruzado la historia de nuestro país. Es en ella donde se han sustentado los procesos privatizadores de las políticas liberales en mayor medida: la salud, la previsión y especialmente la educación quedan en manos de las decisiones familiares, asumiendo su existencia universal y remarcando su valía moral respecto del Estado. La familia decide sobre preceptos de lo privado, asuntos públicos, y es en el caso de la educación donde nuevamente somos testigos de un simulacro respecto a la decisión parental del mejor lugar para educar a los hijos, al creer que la mejor decisión respecto de la educación de los niños de una nación es la que lleva a cabo un grupo familiar, por el sólo hecho de que se supone que la familia resguardaría siempre el bienestar de los suyos, obviando el eje del origen de la neurosis para el psicoanálisis en la familia real o en la novela familiar (Roudinesco, 2002); y sin tomar en cuenta otras variables, como el nivel social, cultural y educativo; o bien, sencillamente, sin comprobar si es efectivo que existe ese entorno familiar detrás de todo niño chileno.

Puede considerarse que en Chile se ha insistido majaderamente en la existencia universal de la familia, una familia nuclear procreadora, orientada al desarrollo de los hijos. Nuestra Constitución, del año 1980, creada bajo el alero de la Dictadura Militar, consigna en la primera parte, dedicada a las bases de la constitucionalidad: "Las personas nacen libres e iguales en dignidad y derechos. La familia es el núcleo fundamental 
de la sociedad"5. Esta familia responde además a un ideal cristiano, donde la vida es el valor fundamental y el respeto a los padres -los adultos- reverencial, donde son considerados detentores de un saber natural por el sólo hecho de ser padres, de haber procreado hijos.

Durante la dictadura militar acaecida en Chile se realizó un fuerte trabajo para solidificar el concepto de familia, ya que sería en el contexto familiar donde se podría lleva a cabo una privatización exitosa. Este trabajo contó con los fundamentos de la Iglesia Católica, que si bien no desarrolla ni profundiza su idea de familia en pro de mejorar las condiciones para las bases privatizadoras, sí podríamos decir que contiene en sus principios material suficiente para allanar el camino de los más conservadores para remarcar el valor de la familia como base de la sociedad ${ }^{6}$.

Ser parte de la familia actual induce a la creencia que ese es el lugar del individuo por antonomasia, en profunda simetría con el modelo económico actual. De hecho, es posible relacionar el origen de la familia nuclear en el Capitalismo y la Modernidad. En su obra clásica "El nacimiento de la familia moderna" de 1977, Edward Shorter plantea que la familia tradicional nace para transmitir la propiedad y las posesiones de una generación a otra organizando de esta manera el capital (Rojas, 2001). Por su parte, también puede entenderse la familia prenuclear como unidad productiva, especialmente en el mundo rural donde tanto los adultos como los niños ocupaban una función económico-material, como mano de obra campesina.

Asimismo, es posible observar cómo la familia ha funcionado como un dispositivo de control, ya que a través de ésta habrían nacido los sentimientos hacia los niños, que permitirían al Estado contar con el grupo familiar en pro de mejoras demográficas. El devenir de estos sentimientos hacia la infancia estaría relacionado, según Badinter (1992), con cambios políticos, que en el caso de Francia, se reflejan en el problema que significaba para la clase política la alta mortalidad infantil, provocada muchas veces por la despreocupación de los padres hacia los recién nacidos. El sentimiento hacia los niños pequeños no era sólido en tanto éstos podían morir con extrema facilidad durante los primeros meses de nacidos, pero ese lazo laxo generaría un círculo vicioso graficado en una mayor despreocupación y por ende una mayor cantidad de fallecimientos de recién nacidos. Es así que la entronización del niño en el centro de la familia debe pasar necesariamente por la construcción del sentimiento maternal, por lo tanto es posible decir que el instinto maternal -como sentimiento natural- no existe, sino que el afecto que

$5 \quad$ En el artículo 19 se habla del derecho a la educación como sigue: "Los padres tienen el derecho preferente y el deber de educar a sus hijos. Corresponderá al Estado otorgar protección especial al ejercicio de este derecho". Más adelante, en el mismo artículo 19, dice: "Prohíbanse las asociaciones contrarias a la moral, el orden público y a la seguridad del Estado". En el año 2006, un grupo de parlamentarios propuso agregar después de la palabra "moral" la siguiente oración "o que atenten contra el orden natural de la familia". Ver proyecto en http://sil.congresonacional.cl. La moción está en trámite.

6 “... es en la escuela de la familia, desde el primer momento, donde se comienza la preparación para el matrimonio y para la vida en sociedad. La familia debe vivir así en la comunión que estimula a cada uno para su crecimiento y para su articulación armónica con el otro como distinto, produciendo la paz y felicidad. Todo ello es experiencia y escuela auténtica del ejercicio del amor. No hay que olvidar esto que también se ha de vivir en los hogares donde falta alguno de los padres, o donde los niños viven con sus abuelos o con otras personas. El hogar familiar es la gran escuela para adquirir las condiciones con las que se puede escuchar en profundidad la vocación para el matrimonio o para la vida sacerdotal o religiosa". Carta Pastoral sobre la Iglesia y la Familia. (2003).www.iglesia.cl 
caracteriza la relación entre madres e hijos es una consecuencia de las necesidades de la sociedad. Badinter (1992) irá más lejos y verá en este proceso de valorización de la maternidad la puesta en atajo del libertinaje propio de las mujeres de la clase alta durante el Absolutismo, es decir, el "instinto maternal" se instala como una institución represora de la mujer.

La Familia se ha consolidado como un modelo de orden social, heredero de las prácticas modernas, donde le cabe un rol controlador y disciplinador. Jacques Donzelot (1976) describe cómo se planificó la recuperación de los niños por parte de las clases altas, sacándolos del cuidado de los empleados y nodrizas, mientras que en los sectores bajos se le adjudicó a la familia un papel moralizador y vigilante de los vicios. Para aquel que quedara fuera de la familia se crearon múltiples instituciones que cumplían el papel de cuidador: hospicios, prostíbulos e instituciones que recogían niños de las calles, ahora bajo las condiciones de la institución y no bajo el calor familiar ${ }^{7}$. A partir de esto es posible abrir una nueva condicionante respecto de la relación Estado-familia: en la medida que el Estado se encoge, la labor familiar crece, la maternidad se hace más acuciante, la decisión parental se vuelve hacia la radicalidad del destino del niño. Los menos favorecidos aún cuentan con un Estado cuidador, pero es un Estado cojo, carente, que se ha transformado más bien en el castigo de aquellos que no tienen el alero familiar. La escuela y el consultorio de salud municipalizados son el recordatorio constante de que hay que salir de ahí, que se puede salir de ahí en búsqueda de otras opciones. Cuando esto es la única opción, es reflejo de que el mundo familiar está fallando, no ha podido llevar a cabo su labor de hacerse cargo.

La creencia de que la familia nuclear es la familia normal, la familia esperable, no es simplemente la consecuencia de un mito. El Estado ha ido construyendo esta realidad en tanto sus políticas suelen adecuarse a ese modelo y no a otros más diversos. Las políticas de vivienda social están dirigidas a grupos familiares pequeños cuando en Chile, por ejemplo, los grupos familiares están conformados no necesariamente por la pareja parental, sino por lazos de parentescos indirectos, fruto generalmente de la convivencia sucesiva entre parejas que no se unen a través del matrimonio. Sin embargo, la familia nuclear, en palabras de Dolto (1986: 68) "es una degeneración de la sociedad", en tanto está encerrada en sí misma, privando a los niños de los recursos de la sociedad y privando a la vez a los padres de las facilidades de ésta. La autora considera que la imposibilidad de llevar a los niños al trabajo es la representación clara de un modelo social nuevo que pone la producción económica exclusivamente en la productividad adulta, cometiendo -en sus palabras- la aberración de alejar a los niños del trabajo hasta que justamente se integran al mundo laboral como adultos.

Las consecuencias políticas además de un sujeto replegado en el mundo familiar pueden ser el peligroso alejamiento de la vida pública, con consecuencias trascendentales en la vida de una sociedad, en tanto los actos de los sujetos quedan detrás del velo protector de la privacidad. Para Arendt "cabe que la subjetividad de lo privado se

7 Foucault hace mención de este fenómeno: “... los economistas y los médicos que estiman que el único lugar posible de remedio de la enfermedad, es el medio natural de la vida social, la familia. En ella, el costo de la enfermedad para la nación se reduce al mínimo; y desaparece también el riesgo de verla complicarse en el artificio, multiplicarse por sí misma y tomar, como en el hospital, la forma aberrante de una enfermedad de la enfermedad". El nacimiento de la clínica (1966: 64). 
prolongue y multiplique en una familia, incluso que llegue a ser tan fuerte que su peso se deje sentir en la esfera pública, pero ese mundo familiar nunca puede reemplazar a la realidad que surge de la suma total de aspectos presentada por un objeto a una multitud de espectadores. Sólo donde las cosas pueden verse por muchos en una variedad de aspectos y sin cambiar su identidad, de manera que quienes se agrupan a su alrededor sepan que ven lo mismo en total diversidad, sólo allí aparece auténticamente la realidad mundana." (Arendt, 2005: 77).

La familia replegada como un espacio controlador, avalado por el Estado privatizador, se constituye en un lugar casi orgánico, origen del individuo y referente de la infancia. Sin embargo, frente a una institución escolar débil es también el lugar dónde se desarrolla el saber, ya sea heredado genéticamente, ya sea entregado por el ejemplo. El niño sabe que es ese su lugar, que sus historias y disfunciones lo acompañan, lo construyen, como si los adultos que lo rodearan los esculpieran, por un lado, pero principalmente, le cerraran las posibilidades de ser otro, de ser distinto a la determinante familiar.

Los niños entrevistados no viven el espacio de lo público, con excepciones que confirman la regla, cuando dicen: "deberíamos discutir cómo mejorar la educación, pero nos quedamos pegados en otra cosa" ${ }^{\circ}$, claudicando rápidamente al esfuerzo que amerita lo público, lo que no puede funcionar bajo la lógica de un eterno control.

El repliegue del niño en la familia es la muestra clara de una sociedad que no desea a los niños sino que encerrados: la responsabilidad sobre el niño queda clausurada en las familias, las que no dejan de ser entes en constante construcción, frágiles, indeterminados y carentes en algunos casos, fuente de desigualdad y frustración más que determinantes de la solidez de los sujetos que en ella habitan.

Por otro lado, el mundo cultural, que es en definitiva el mundo del saber esperado por la escuela, queda afuera de la esfera íntima, queda excluido del mundo infantil desde temprana edad dejando de obrar el principal rol de una sociedad: recibir a los nuevos, integrarlos y dejarlos que constituyan la cultura. Llama la atención la ausencia en el discurso de los niños su vida afuera de la escuela, una vida a veces descrita como monótona, solitaria, ausente.

Una sociedad que se cierra a esta posibilidad es una sociedad que se carcome a sí misma. Pero la realidad dista de ser solidaria con los recién llegados. Por el contrario, se han reforzado las ideas del encierro infantil, de la protección, de la salida de las calles y plazas. El camino de algunos países desarrollados es cerrar las puertas de ciertos lugares a la presencia infantil, simplemente porque los niños molestan o, en otros casos, por protección. ¿Cuántas veces esta protección es la violación flagrante de los derechos constitucionales de los niños? Es algo que hay que preguntarse. Que la propia Constitución chilena deje la labor educativa a las familias, es la renuncia a hacerse cargo, la sociedad nacional completa, del recibimiento del niño en el mundo cultural.

Entonces, ¿qué lugar queda al niño? La familia y la escuela, pero ¿cómo conocer en un mundo controlado como la escuela? ¿Cómo crecer en un espacio cerrado como las familias de la privatización? Son las relaciones subjetivas y no las instituciones las que han sustentado el desarrollo de los niños. Son los afectos y no los sentimientos los que han preservado su deseo.

8 Varón, 10 años, $5^{\circ}$ básico, Colegio Particular. 


\section{BIBLIOGRAFIA}

Arendt, Hannah (1989). Entre el Pasado y el Futuro. 8 ejercicios sobre la Reflexión Política. La crisis de la educación (1954). Barcelona: Ed. Península.

Arendt, Hannah (2005). La condición humana (1958). Barcelona: Paidós Surcos.

Ariés, Philippe (1987). El Niño y la Vida Familiar en el Antiguo Régimen (1973). Madrid: Taurus.

Badinter, Elizabeth (1992). ¿Existe el amor maternal?: historia del amor maternal (s. XVIII-XX). Barcelona: Ediciones Paidós Ibérica.

Banks, Markus (1995). "Visual research methods". Social Research Update 11. ww.soc.surrey. ac.uk/sru/SRU11/SRU11.html.

Burman, Erika (1994). La deconstrucción de la Psicología Evolutiva. Aprendizaje-Visor: Madrid.

Deleuze, Gilles (1985). La imagen del tiempo. Estudios sobre cine 2. Barcelona: Paidós.

Deleuze, Gilles (1987). Foucault. Barcelona: Paidós.

Dolto, Francoise (1990). La Imagen Inconsciente del Cuerpo (1984). Barcelona: Editorial Paidós.

Donzelot, Jacques (1990). La Policía de las familias. Valencia: Pre-Textos.

Font, Vicenc (2003). "Matemáticas y Cosas. Una Mirada desde la Educación Matemática". Boletín de la Asociación Matemática Venezolana, Vol. X, N² 2. pp. 249-276.

Foucault, Michel (2006). El nacimiento de la clínica: Una arqueología de la mirada médica (1966). Buenos Aires: Siglo XXI Editores.

Foucault, Michel (2002). El Orden del Discurso (1973). Barcelona: Fábula Tusquets Editores.

Harper, Douglas (2002). “Talking about pictures: a case for photo elicitation”. Visual studies, Vol. 17, $\mathrm{N}^{\mathrm{o}} 1$.

Hazel, Neal (1995). "Elicitation techniques with young people". Social Research Update 12. www.soc.surrey.ac.uk/sru/SRU12.html.

Illanes, M. Angélica (1991). Ausente, señorita: El niño chileno, la escuela para pobres y el auxilio. 1890/1990. Santiago de Chile: JUNAEB.

James, A. \& Prout, A. (1997). A new Paradigm for the sociology of Childhood: Provenance, Promise and Problems. Constructing and Reconstructing Childhood: Contemporary issues in the sociological study of childhood. Editorial by Allison James and Alan Prout. London: Falmer Press.

Merleau-Ponty, M. (1953). La Estructura del Comportamiento. Buenos Aires: Librería Hachette de Filosofía.

Milanich, Nara (2001). "Los Hijos de la Providencia: El abandono como circulación en el Chile decimonónico". Revista de Historia Social y de las Mentalidades $\mathrm{N}^{\circ} 5$, Universidad de Chile. Santiago, pp. 79-100.

Montecinos, Sonia (1991). De madres y huachos. Alegorías del Mestizaje chileno. Santiago de Chile: Editorial Sudamericana.

Piaget, Jean (2000). La formación del símbolo en el niño (1959). México: Fondo de Cultura Económica.

Piaget, Jean (1985). Biología y conocimiento: ensayo sobre las relaciones entre las regulaciones orgánicas y los procesos cognoscitivos (1967). México: Siglo Veintiuno.

Piaget, Jean (1975). Introducción a la epistemología genética. Buenos Aires: Paidós.

Rojas, Jorge (2001). "Los niños y su historia: Un acercamiento conceptual y teórico desde la historiografía". Revista Electrónica de Historia $\mathrm{N}^{\circ} 1$. www.pensamientocrítico.cl.

Roudinesco, Elizabeth (2002). La Familia en desorden. Buenos Aires: Fondo de Cultura Económica.

Rousseau, Jean-Jacques (1983). El Contrato Social. Madrid: Sarpe. 
Rousseau, Jean-Jacques (1990). Emilio o De la Educación. Madrid: Alianza Editorial.

Salazar, G. y Pinto, J. (2003). Historia Contemporánea de Chile V: Niñez y Juventud. Santiago de Chile: LOM Editores.

Salazar, Gabriel (1990). "Ser niño huacho en la Historia de Chile (Siglo XIX)". Proposiciones, $\mathrm{N}^{\circ} 19$, pp. $55-72$.

Salazar, Gabriel (2007). Ser niño huacho en la Historia de Chile (Siglo XIX). Santiago: Lom.

Varela, Francisco (2000). El Fenómeno de la Vida. Santiago de Chile: Dolmen. 
